\title{
Diagnosis of cytomegalovirus infection and disease
}

Human cytomegalovirus (CMV) is a ubiquitious member of the herpesvirus family. In the UK, 40$50 \%$ of healthy blood donors are seropositive, indicating previous exposure [1]. Primary infection or reactivation of $\mathrm{CMV}$ in healthy individuals is either subclinical or self-limiting. However, in immunocompromised individuals, such as patients receiving solid organ or bone marrow transplantation, in patients with acquired immunodeficiency syndrome (AIDS), or in congenital infections, a significantly adverse clinical course and outcome can be seen. Now that effective antiviral agents such as ganciclovir, foscarnet and cidofovir are available for the treatment of CMV disease, patients will benefit from early and accurate diagnosis and treatment.

One major problem in CMV diagnosis is the differentiation between infection and disease. Traditionally, the detection of owl-eyed inclusion bodies in tissues has been considered to be a strong indicator of active CMV disease [2]. However, this method is very insensitive and the intranuclear inclusions can occasionally be confused with inclusions caused by other herpesviruses or adenoviruses. The use of immunocytochemistry or DNA hybridisation improves both sensitivity and specificity [3]. Although tissue diagnosis remains important for localised CMV disease such as hepatitis and colitis, it is limited in many situations by the need to use invasive procedures to obtain samples. Conventional virological methods include culture of body fluids and serology. Both have significant drawbacks in that conventional cell culture takes at least 7-14 days and sometimes up to 4 weeks for the recognition of a cytopathic effect, and serology (complement fixation test, detection of IgG and $\operatorname{IgM}$ ) may be unreliable in immunocompromised patients. More importantly, although a positive result indicates the presence of CMV infection or activity, it does not necessarily imply CMV disease.

The problem of the need for prolonged culture for virus isolation was solved by the introduction of rapid shell vial cell culture with detection of early antigen fluorescent foci with monoclonal antibodies (MAbs) against immediate-early proteins of CMV [4]. By this method, CMV can be detected in cell culture as early as $16 \mathrm{~h}$ after inoculation and almost any body fluid or tissue can be cultured. The detection of virus in blood by this method appears to be of prognostic significance and is predictive of CMV disease [5]. It is also possible to quantify viraemia by standardising the number of leucocytes in the inoculum and counting the number of positive foci. The results of this leucocyte test, however, are quite variable as its success depends on factors such as: the susceptibility of cell lines; the number of polymorphs and mononuclear cells inoculated; the use of multiple shell vials per sample; the use of centrifugation or chemical enhancement; incubation duration prior to fixation and staining; and the frequently encountered problem of inoculum toxicity [6-8].

A more rapid approach is the direct detection of CMV antigen in clinical samples. With the pp65 direct antigenaemia test, MAb directed against the CMV lower matrix protein pp65 is used for the direct detection of $\mathrm{CMV}$ in cytospin preparations of leucocytes by use of immunofluorescence or immunoperoxidase techniques. The demonstration of positive staining signals in the nuclei of polymorphs indicates a positive result. Maintenance of cell culture is not required and the success of the assay does not depend on viable virus in the samples. In-vitro studies have shown that the intranuclear accumulation of pp65 antigen occurs before translation of CMV immediateearly protein and viral replication [9]. The procedure takes about $4 \mathrm{~h}$ and is semi-quantitative as the number of positive polymorphs in a smear can be counted. It is sensitive and has good correlation with CMV disease in both AIDS patients and organ transplant recipients [10-12]. In renal transplant recipients, it has been suggested that the presence of 10 positive polymorphs per 50000 leucocytes represents significant antigenaemia [13]. However, in more heavily immunosuppressed patients such as those undergoing allogenic bone marrow transplantation, the presence of any level of antigenaemia could be significant [14]. The main drawbacks of the antigenaemia test are that it is labour intensive and that freshly taken samples are needed. A delay of sample processing for $\geqslant 24 \mathrm{~h}$ results in a significant decrease in the number of detectable pp65-positive cells $[15,16]$. Therefore, the antigenaemia test is of little value to clinicians who do not have access to an on-site laboratory that offers this test. Also, because the antigenaemia test depends on the presence of polymorphs, it may give false negative results in patients who are neutropenic.

Molecular amplification methods such as the polymerase chain reaction (PCR) have been used to study 
CMV infection with samples such as urine, leucocytes plasma and serum [17-19]. One concern is that the use of such an ultra-sensitive technique would result in poor positive predictive value for disease [20]. The sensitivity of PCR depends on a number of factors such as the type of anticoagulant used for specimen collection, the choice of primers, the use of nested PCR, the amount of sample used per assay and the format of PCR product detection [17]. A commercial PCR assay (Roche Amplicor, Switzerland) is now available and this may help to standardise results between laboratories. The quantification of viral load by PCR is another promising development that could be important for the diagnosis and prediction of CMV disease and for the monitoring of therapy [19, 21]. It is not certain whether all forms of CMV disease have the same correlation with CMV viral load and it is possible that different patient groups have a different viral load threshold for disease. An important advantage of amplification methods over antigen detection is that samples can be stored at room temperature for up to $72 \mathrm{~h}$ before processing with no significant alteration in the level of detectable DNA [16]. This means that samples can be sent by ordinary post to a reference laboratory with no loss of positivity. To avoid the problem of possible false positive results or sporadic unexplained positive amplification, many centres with a policy of preemptive therapy for CMV perform serial surveillance and will act only on consecutive positive PCR results $[22,23]$.

Commercial assays for the detection of viral DNA in whole blood or leucocytes by hybridisation techniques are also available. In the hybrid capture assay (Digene, USA; Murex, UK) an RNA probe is used to hybridise with viral DNA and the resultant hybrid is then captured by a MAb specific for DNA:RNA hybrids [24]. In the bDNA assay (Chiron, USA) branched DNA amplifiers are used to effect signal amplification during hybridisation [25]. Chemiluminescence is used for signal detection in both methods and can provide quantitative results. Although hybridisation assays are in general expected to be less sensitive than PCR, the range of detection of DNA is probably sufficient for use in CMV diagnosis. Also, quantification of DNA by a hybridisation assay is likely to be more accurate because the kinetics are linear rather than exponential.

To identify active viral replication, some workers have developed amplification assays for viral mRNA in leucocytes [26]. Preliminary results have shown that mRNA detection, although less sensitive than conventional PCR assay, correlates with disease [23, 27]. A commercial assay based on the isothermal technique of nucleic acid sequence based amplification (Organon Teknika, The Netherlands) has been developed to amplify the mRNA of CMV matrix protein pp67.
Further work is necessary to determine whether these assays are clinically useful.

Recent developments in the field of CMV diagnosis are exciting. The increasing use of CMV surveillance and pre-emptive therapy for CMV means that there is a need for sensitive tests that become positive well before the onset of symptoms. Several of the new molecular methods described above fulfil this criterion. The ability to quantify viral load not only helps to predict outcome, but this will be an important tool in the investigation of pathogenesis and to monitor therapeutic response. The high sensitivity of these new assays will allow early diagnosis of CMV infection, but it is necessary to compare the different assays to identify those which have the best predictive value of CMV disease. When confronted with a symptomatic patient who may have CMV disease and a quick result is needed for action, the pp65 direct antigenaemia test is the test of choice.

C. Y. W. TONG

Department of Medical Microbiology and Genitourinary Medicine, University of Liverpool Liverpool L69 3GA

\section{References}

1. Grint PCA, Ronalds CJ, Kangro HO. et al. Screening tests for antibodies to cytomegalovirus: an evaluation of five commercial products. J Clin Pathol 1985; 38: 1059-1064.

2. Wong TW, Warner NE. Cytomegalic inclusion disease in adults: report of 14 cases with review of literature. Arch Pathol 1962; 74: 403-422.

3. Myerson D, Hackman RC, Meyers JD. Diagnosis of cytomegaloviral pneumonia by in-situ hybridization. J Infect Dis 1984; 150: 272-277.

4. Stirk PR, Griffiths PD. Use of monoclonal antibodies for the diagnosis of cytomegalovirus infection by the detection of early antigen fluorescent foci (DEAFF) in cell culture. $J \mathrm{Med}$ Virol 1987; 21: 329-337.

5. Pillay D, Ali AA, Liu SF, Kops E, Sweny P, Griffiths PD. The prognostic significance of positive CMV cultures during surveillance of renal transplant recipients. Transplantation 1993; 56: 103-108.

6. Saltzman RL, Quirk MR, Jordan MC. Disseminated cytomegalovirus infection. Molecular analysis of virus and leukocyte interactions in viremia. $J$ Clin Invest 1988; 81: 75-81.

7. Buller RS, Bailey TC, Ettinger NA et al. Use of a modified shell vial technique to quantitate cytomegalovirus viremia in a population of solid-organ transplant recipients. $J$ Clin Microbiol 1992; 30: 2620-2624.

8. West PG, Hartwig RA, Baker WW. Comparison of sensitivities of three commercial MRC-5 cell lines grown in shell vials to cytomegalovirus and responses to enhancing agents. $J$ Clin Microbiol 1992; 30: 557-560.

9. Grefte JMM, van der Gun BTF, Schmolke S et al. The lower matrix protein pp65 is the principal viral antigen present in peripheral blood leukocytes during an active cytomegalovirus infection. J Gen Virol 1992; 73: 2923-2932.

10. Ehrnst A, Barkholt L, Brattström $\mathrm{C}$ et al. Detection of CMVmatrix pp65 antigen in leukocytes by immunofluorescence as a marker of CMV disease. J Med Virol 1993; 39: 118-124.

11. Bek B, Boeckh M, Lepenies J et al. High-level sensitivity of quantitative pp65 cytomegalovirus (CMV) antigenemia assay for diagnosis of CMV disease in AIDS patients and follow-up. $J$ Clin Microbiol 1996; 34: 457-459.

12. Sharma AK, Taylor JD, Tong W, Brown MW, Sells RA, Bakran A. Utility of the pp65 antigenemia test in the diagnosis of cytomegalovirus (CMV) in renal transplant recipients. 
Transplant Proc 1997; 29: 799.

13. Van Den Berg AP, Van Der Bij, Van Son WJ et al. Cytomegalovirus antigenemia as a useful marker of symptomatic cytomegalovirus infection after renal transplantation - a report of 130 consecutive patients. Transplantation 1989; 48: 991-995.

14. Boeckh M, Bowden RA, Goodrich JM, Pettinger M, Meyers JD. Cytomegalovirus antigen detection in peripheral blood leukocytes after allogenic marrow transplantation. Blood 1992; 80: $1358-1364$

15. Boeckh M, Woogerd PM, Stevens-Ayers T, Ray CG, Bowden RA. Factors influencing detection of quantitative cytomegalovirus antigenemia. $J$ Clin Microbiol 1994; 32: 832-834.

16. Schäfer P, Tenschert W, Gutensohn K, Laufs R. Minimal effect of delayed sample processing on results of quantitative PCR for cytomegalovirus DNA in leukocytes compared to results of an antigenemia assay. $J$ Clin Microbiol 1997; 35: 741-744.

17. Grundy JE, Ehrnst A, Einsele $\mathrm{H}$ et al. A three-center European external quality control study of PCR for detection of cytomegalovirus DNA in blood. J Clin Microbiol 1996; 34: $1166-1170$.

18. Brytting M, Xu W, Wahren B, Sundqvist V-A. Cytomegalovirus DNA detection in sera from patients with active cytomegalovirus infections. J Clin Microbiol 1992; 30: 1937-1941.

19. Fox JC, Kidd IM, Griffiths PD, Sweney P, Emery VC. Longitudinal analysis of cytomegalovirus load in renal transplant recipients using a quantitative polymerase chain reaction: correlation with disease. J Gen Virol 1995; 76: 309-319.

20. Delgado R, Lumbreras C, Alba $\mathrm{C}$ et al. Low predictive value of polymerase chain reaction for diagnosis of cytomegalovirus disease in liver transplant recipients. J Clin Microbiol 1992; 30: $1876-1878$
21. Gerna G, Furione M, Baldanti F, Sarasini A. Comparative quantitation of human cytomegalovirus DNA in blood leukocytes and plasma of transplant and AIDS patients. $J$ Clin Microbiol 1994; 32: 2709-2717.

22. Yuen K-Y, Lo SK-F, Chiu EK-W et al. Monitoring of leukocyte cytomegalovirus DNA in bone marrow transplant recipients by nested PCR. J Clin Microbiol 1995; 33 $2530-2534$.

23. Gozlan J, Laporte JP, Lesage $\mathrm{S}$ et al. Monitoring of cytomegalovirus infection and disease in bone marrow recipients by reverse transcription-PCR and comparison with PCR and blood and urine cultures. J Clin Microbiol 1996; 34: 2085-2088.

24. Mazzulli T, Wood S, Chau R, Walmsley S. Evaluation of the Digene Hybrid Capture system for detection and quantitation of human cytomegalovirus viremia in human immunodeficiency virus-infected patients. J Clin Microbiol 1996; 34: 2959-2962.

25. Myerow S, Lee M, Shen L-P et al. Development of a branched DNA (bDNA) assay with improved sensitivity for monitoring CMV viral load in immunocompromised individuals. 6th International Cytomegalovirus Workshop, Alabama, USA, 5-9 March 1997. Abstract no. 179.

26. Gozlan J, Caburet F, Tancrede C, Petit J-C. A reverse polymerase chain reaction method for detection of human cytomegalovirus late transcripts in cells infected in vitro. J Virol Methods 1992; 40: 1-10.

27. Gozlan J, Salford J-M, Chouaid C et al. Human cytomegalovirus (HCMV) late-mRNA detection in peripheral blood of AIDS patients: diagnostic value of HCMV disease compared with those of viral culture and HCMV DNA detection. $J$ Clin Microbiol 1993; 31: 1943-1945. 